\title{
Compresión radicular L5 extraforaminal por músculo psoas accesorio
}

\author{
Jorge Magaña Reyes, ${ }^{1}$ Luis Gerardo Domínguez Gasca, ${ }^{2}$ Luis Gerardo Domínguez Carrillo ${ }^{3}$
}

Masculino de 42 años con dos meses de sintomatología caracterizada por dolor (7/9 en la EVA) localizado en la región glútea izquierda, irradiado a la cara posterolateral del muslo ipsilateral hasta la cabeza del peroné, acompañado de parestesias en la misma área; el dolor se exacerbaba con ejercicio y manejo de automóvil; no presentaba lumbalgia. La molestia inició inmediatamente después de la realización de ejercicio (doble elevación de las extremidades pélvicas con rodillas en extensión, en posición supina). A la exploración: postura y marcha normales; examen clínico muscular normal excepto para el glúteo medio y bíceps crural izquierdos en 4/5; hipoestesia en la cara posterolateral del muslo; el resto, normal; reflejos osteotendinosos, pulsos arteriales y llenado capilar normales. Fue manejado con AINE por dos meses, sin cambio en la sintomatología; fue enviado a rehabilitación, con diagnóstico presuntivo de síndrome facetario con datos de irritación radicular L5 incompleta. Se solicitó una resonancia magnética, donde se encontró músculo psoas accesorio izquierdo (Figuras 1 y 2) responsable de la sintomatología por compresión extraforaminal de la raíz L5 izquierda; fue sometido a un programa de rehabilitación (16 sesiones) con ejercicios de Williams y estiramiento de los flexores de cadera. Fue dado de alta asintomático.

\footnotetext{
${ }^{1}$ Radiólogo. Hospital Ángeles León.

2 Residente de Traumatología y Ortopedia. Hospital General de León, Guanajuato.

3 Especialista en Medicina de Rehabilitación. Profesor de la Facultad de Medicina de León. Universidad de Guanajuato. México.
}

Correspondencia:

Dr. Luis Gerardo Domínguez Carrillo

Correo electrónico: Igdominguez@hotmail.com

Aceptado: 31-08-2016.

Este artículo puede ser consultado en versión completa en http://www. medigraphic.com/actamedica

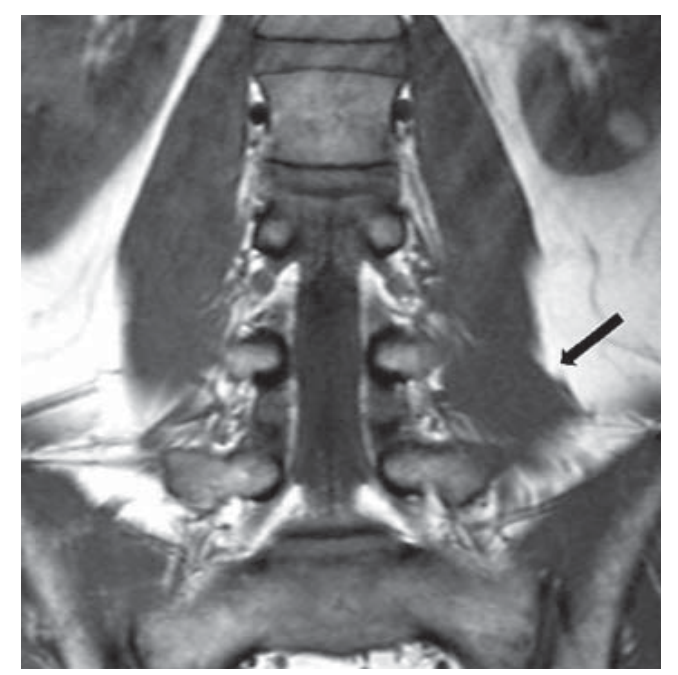

Figura 1. Imagen de resonancia magnética en secuencia coronal, ponderada en T1, a nivel del conducto medular a la altura de L4-L5, donde se identificó en situación paraespinal izquierda una imagen isointensa al músculo, de morfología triangular (flecha), justo sobre el trayecto de las raíces emergentes, correspondiendo a músculo psoas accesorio.

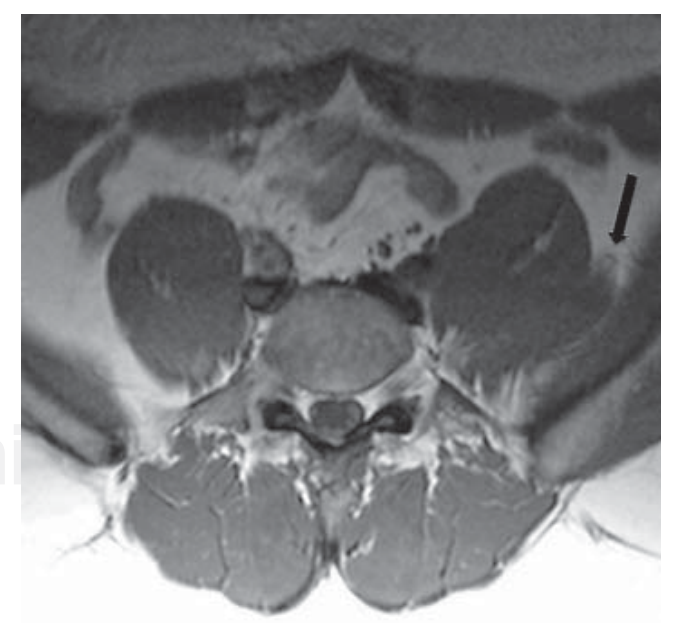

Figura 2. Imagen de resonancia magnética en secuencia axial ponderada en T1, que muestra obliteración de la señal de la grasa posterior al psoas lumbar izquierdo por músculo psoas accesorio (flecha); compárese con el lado contralateral. 
En la literatura se reportan varias anomalías del músculo psoas-iliaco; ${ }^{1}$ se desconoce su prevalencia, ya que la gran mayoría son asintomáticas. Jelev y sus colaboradores ${ }^{2}$ reportan un músculo iliopsoas accesorio entre 108 autopsias efectuadas durante 22 años. Las anomalías del psoas iliaco se localizan más frecuentemente a nivel de su inserción distal; ${ }^{3}$ a veces, estas variaciones anatómicas pueden ser sintomáticas (como en el caso presentado), ocasionando compresión radicular de L4 y/o L5 a nivel extraforaminal ${ }^{4} \mathrm{o}$ afección del nervio femoral, ${ }^{5}$ que requieren ser estudiadas como parte del diagnóstico diferencial de compresión radicular.

\section{REFERENCIAS}

1. Fabrizio PA. Anatomic variation of the iliacus and psoas major muscles. International Journal of Anatomical Variations. 2011; 4: 28-30.

2. Jelev L, Shivarov V, Surchev L. Bilateral variations of the psoas major and the iliacus muscles and presence of an undescribed variant muscle —accessory iliopsoas muscle. Ann Anat. 2005; 187 (3): 281-286.

3. Philippon MJ, Devitt BM, Campbell KJ, Michalski MP, Espinoza C, Wijdicks CA et al. Anatomic variance of the iliopsoas tendon. Am J Sports Med. 2014; 42 (4): 807-811.

4. Lee S, Kang JH, Srikantha U, Jang IT, Oh SH. Extraforaminal compression of the L-5 nerve root at the lumbosacral junction: clinical analysis, decompression technique, and outcome. J Neurosurg Spine. 2014; 20 (4): 371-379.

5. Aristotle S, Sundarapandian S, Felicia C. Accessory iliacus muscle with splitting of the femoral nerve: a case report. OA Case Reports, 2013; 12 (6): 56. 